\title{
Province and ethnic specific prevalence of diabetes among Sri Lankan adults
}

\author{
P Katulanda ${ }^{1,2}$, D A V Rathnapala², R Sheriff ${ }^{2}$, D R Matthews ${ }^{1}$ \\ Sri Lanka Journal of Diabetes Endocrinology and Metabolism 2011; 1: 2-7 \\ (Index words: prevalence, diabetes, Sri Lanka, province, obesity)
}

\begin{abstract}
Objective: To determine the province and ethnic specific prevalence and correlates of diabetes mellitus among Sri Lankan adults.

Method: A nationally representative sample of 5000 adults aged $\geq 18$ years was selected by a multistage random cluster sampling technique in this cross-sectional study conducted between 2005 and 2006.

Results: Response rate was $91 \%(n=4532)$, males were $40 \%$, age $46.1 \pm 15.1$ years (mean \pm SD). The age-sex standardized prevalence $(95 \% \mathrm{Cl}$ ) of diabetes for Sri Lankans aged $\geq 20$ years has been previously published as $10.3 \%(9.4-11.2 \%)$ [males $9.8 \%(8.4-11.2 \%)$, females $10.9 \%(9.7-12.1 \%), P=0.129)$. There was a marked variation in the province specific prevalence of diabetes with the highest $(18.6 \%)$ in the Western and the lowest (6.8\%) in the Uva provinces. The monthly income, BMI, waist circumference and per capita monthly expenditure were highest in the Western and lowest in the Uva. In contrast, the mean physical activity level was lowest in the Western province and highest in the Uva. However, the per capita daily energy consumption was lowest in the Western and highest in the Uva provinces.

The Sri Lankan Tamil ethnicity has the highest $(22.1 \%)$ diabetes prevalence followed by the Sri Lankan Moor (21.4\%). The Indian Tamil ethnic group living in the plantation sector had the lowest prevalence.

Conclusions: The provincial and ethnic distribution of diabetes closely resembled that of obesity (waist circumference more than the $\mathrm{BMI}$ ) and the income level in the respective provinces and ethnic groups. The physical activity level had an inverse relationship. High level of physical activity had a protective effect from diabetes even when the energy consumption is high.
\end{abstract}

\section{Introduction}

In 2002 World Health Organization (WHO) stated that "in many regions, some of the most formidable enemies of health are joining forces with the allies of poverty to impose a double burden of disease, disability and premature death in many millions of people" (1). This is what is happening in South Asia, where one quarter of the global population lives and about half of it below the poverty line with limited access to health care. Although infectious diseases remain a formidable enemy, the population is ageing and noncommunicable diseases are rising. Diabetes has become a major and growing contributor to mortality and disability in South Asia (2).

An understanding of the population at risk of developing the disease is critical when projecting future disease burden. Accumulating research shows that there are number of factors which contribute to a person's overall likelihood of developing type 2 diabetes and heart disease
(3). Several surveys on risk factors conducted across South Asian countries have shown high and rising rates of overweight, central obesity, high blood glucose levels high blood pressure and dyslipidaemia in urban populations (3). Such trends also exist in rural populations but are lower in magnitude and less steep in the slope of change $(4,5)$. Although ethnic differences in prevalence of type 2 Diabetes are well documented in European and American communities, there is paucity of data among Asians within a single country.

Sri Lanka is a middle-income country with a population of 20.7 million people (6) and the population comprises of two broadly different socio-demographic groups, namely urban and rural. The urban population has higher income and leads a more westernized lifestyle compared to the rural population, where the majority is engaged in agriculture and related occupations, with lower income levels and a more physically active lifestyle. There are four main ethnic groups, namely Sinhalese, Sri Lankan

${ }^{1}$ Oxford Centre for Diabetes Endocrinology and Metabolism, University of Oxford, UK. ${ }^{2}$ Diabetes Research Unit, Faculty of Medicine, University of Colombo, Sri Lanka. 
Tamils, Indian Tamils and Sri Lankan Moors. No countrywide surveillance system for non-communicable diseases exist in Sri Lanka and the prevalence of diabetes has been determined by epidemiological surveys. Studies in rural areas have shown an increase in the prevalence of diabetes from $2.5 \%$ in 1990 (7) to $8.5 \%$ in 2000 (8). In the suburban populations, the prevalence has been reported as $5.0 \%$ in 1994 (9) and $6.6 \%$ in 2002 (10). In a mixed urban and rural population, the prevalence was reported as $5.8 \%$ in 1994 (11). In 2005, a study carried out in adults between 35 and 65 years of age in four provinces in Sri Lanka reported diabetes prevalence of $14.2 \%$ in men and $13.5 \%$ in women (12). The Sri Lanka Diabetes and Cardiovascular Study (SLDCS) was carried out in 2005 to bridge the gap of data and we have previously reported the national prevalence of diabetes mellitus in Sri Lanka as 10.3\% (13).

In this paper we present the province and ethnic specific prevalence of diabetes in the adult population in Sri Lanka based on SLDCS, these data are important for public health action.

\section{Patients and methods}

The Sri Lanka Diabetes and Cardiovascular Study (SLDCS) was conducted by the Diabetes Research Unit of the University of Colombo and the Oxford Centre for Diabetes Endocrinology and Metabolism, UK. It was a cross sectional study, approved by the Ethical Review Committee of the University of Colombo. Data collection was between August 2005 and September 2006. All participants provided informed written consent.

\section{Participants}

This study was done in seven of the nine provinces in Sri Lanka. Detail method of sampling and data collection has been reported previously (13).

\section{Data collection}

Data collection was carried out by a team of trained medical graduates and nurses. The selected subjects were invited to the temporary established data collection centres within each cluster. Routine unrestricted diet with usual physical activities at least 3 days prior to the data collection was recommended. They were advised to fast 12 hours from the day prior to data collection. An intervieweradministered questionnaire was used for data collection. Anthropometric measurements were performed according to the standard methods using calibrated equipment (14). Seated blood pressure was recorded on two occasions after a 10-min rest using an Omron IA2 digital blood pressure monitor (Omron Healthcare, Asia-Pacific Region, Singapore). Fasting venous blood samples were obtained for glucose and lipid estimation from all participants. Those not known to have diabetes underwent an oral glucose tolerance test (OGTT) by taking glucose monohydrate equivalent to $75 \mathrm{~g}$ of anhydrous glucose in $300 \mathrm{ml}$ of water within a period of $5 \mathrm{~min}$ followed by 2 hour blood samples $(n=4084)$. Details of the storage and analysis of blood samples were previously reported (13).

\section{Definitions}

Subjects were considered to have 'diagnosed diabetes' if they had been previously diagnosed at a government hospital or by a registered medical practitioner. Verification was by review of previous medical records, laboratory reports or prescriptions. New cases ('undiagnosed diabetes') were diagnosed according to the American Diabetes Association (ADA) and WHO criteria $(15,16)$. Physical activity was recorded using the short format of the International Physical Activity Questionnaire (IPAQ) (17). Urban and rural sectors were defined according to the classification of the Sri Lankan government (18). Those who were detected to have diabetes or other medical problems at SLDCS were referred to the closest government medical centre for necessary follow-up.

\section{Statistical analysis and projections}

Data analysis was done using SPSS version 14 (SPSS Inc., Chicago, IL, USA) and Stata/SE 10.0 (Stata Corporation, College Station, TX, USA) statistical software packages. Point estimates for prevalence were obtained for diabetes and pre-diabetes using the Stata survey data analysis adjusted for the stratified cluster sampling model. Samples were weighted for the differences in house hold and cluster-level participation. The significance of the differences between proportions (\%) and means were tested using $\chi 2$-test and Student's $t$-test or ANOVA respectively $P$ values $<0.05$ were considered significant.

\section{Results}

4532 participated in the study. The response rate was $91 \%$. Data from 4388 subjects aged $\geq 20$ years were used for prevalence estimation. (47 were excluded due to incomplete data) The sample consisted of $40 \%$ males. $18 \%$ of subjects were from urban areas. The mean age ( \pm standard deviation) was $46.1 \pm 15.1$ years (males $46.3 \pm$ 15.8 , females $46.0 \pm 14.6$ ).

As reported previously the overall crude prevalence of diabetes in the sample was $12.6 \%(n=536)(13)$.

\section{Province specific prevalence of diabetes}

There was a marked variation in the province specific prevalence of diabetes with $18.6 \%$ in the highest (Western) and $6.8 \%$ in the lowest (Uva) (Figure 1 and Table 1) provinces. The sample from the Western Province had a lower mean age compared to all the other provinces except the North Central Province. The provinces with higher prevalence of diabetes also had higher mean income, BMI, 


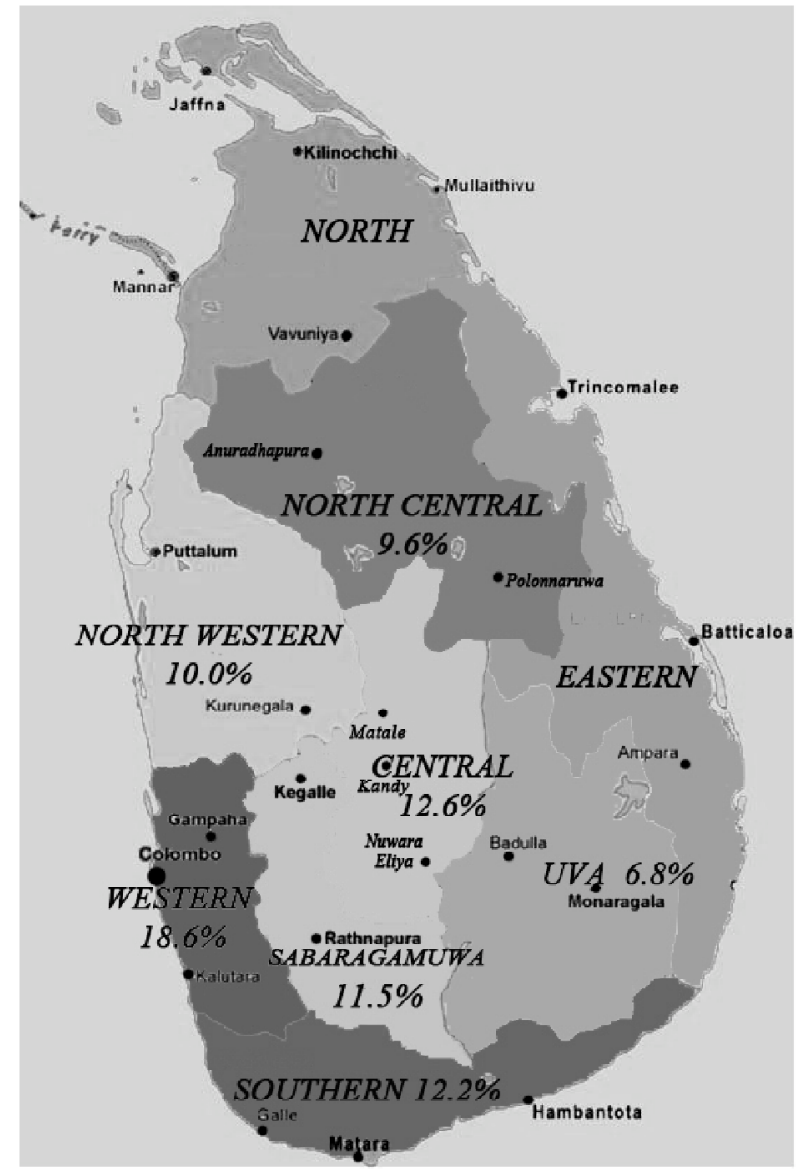

Figure 1. Diabetes map of Sri Lanka. waist circumference, total per-capita monthly expenditure and lower levels of activity (Met-minutes) compared to the provinces with lower prevalence of diabetes $(\mathrm{p}<0.001$ for diabetes, income, BMI, waist circumference and physical activity between provinces). The mean per-capita energy consumption was lowest in the Western Province, in spite of having the highest prevalence of diabetes, obesity and, income. In contrast, despite having the highest daily energy consumption (according to the data from the Household Income and Expenditure Survey 2006/ 2007 - (Department of Census and Statistics Sri Lanka, 2008), diabetes prevalence remained lowest in the Uva province which has the highest mean energy expenditure.

\section{Ethnic specific prevalence of diabetes}

The weighted prevalence of diabetes and underlying correlates among those belonging to the four main ethnic groups in Sri Lanka are shown in Table 2. The weighted prevalence of diabetes for each ethnic group was calculated according to the self disclosed ethnicity of the study participants using the STATA software (Stata Corp LP., Texas, USA). Accordingly, the Sri Lankan Tamil ethnicity has the highest prevalence of diabetes followed by the Sri Lankan Moor. The Indian Tamil ethnic group has the lowest prevalence of diabetes. Similar to the patterns observed in the different provinces, diabetes was higher in ethnic groups with higher levels of waist circumference, BMI, income and lower levels of physical activity (Figure 2).

Table 1. Province specific prevalence of diabetes, risk factors and socio-demographic correlates in Sri Lankan adults

\begin{tabular}{|c|c|c|c|c|c|c|c|c|}
\hline Province & $\begin{array}{l}\text { Prevalence } \\
\text { of diabetes: } \\
(95 \% \text { CI) }\end{array}$ & $\begin{array}{l}\text { Mean } \\
\text { age } \\
\text { (years) }\end{array}$ & $\begin{array}{l}\text { Mean } \\
\text { income } \\
(L K R)\end{array}$ & $\begin{array}{l}\text { Mean } \\
\text { activity } \\
\text { (Met- } \\
\text { minutes) }\end{array}$ & $\begin{array}{l}\text { Mean BMI } \\
\left(\mathrm{kg} / \mathrm{m}^{2}\right)\end{array}$ & $\begin{array}{l}\text { Mean } \\
\text { waist } \\
\text { circum- } \\
\text { ference } \\
(\mathrm{cm})\end{array}$ & $\begin{array}{l}\text { Per-capita } \\
\text { total } \\
\text { monthly - } \\
\text { expenditure } \\
(L K R)^{*}\end{array}$ & $\begin{array}{l}\text { Per-capita } \\
\text { daily } \\
\text { energy } \\
\text { consum- } \\
\text { ption } \\
(\text { Kcal })^{*}\end{array}$ \\
\hline Western & $18.6(15.8-21.5)$ & 44.5 & 13609 & 2721 & 23.6 & 83.3 & 6935 & 1977 \\
\hline Central & $12.6(9.3-15.9)$ & 47.5 & 10459 & 3848 & 21.6 & 78.1 & 4560 & 2210 \\
\hline Southern & $12.2(8.5-15.9)$ & 48.8 & 7978 & 3528 & 21.7 & 78.0 & 5302 & 2151 \\
\hline Sabaragamuwa & $11.5(7.5-15.5)$ & 47.1 & 8193 & 5984 & 21.3 & 73.8 & 3982 & 2138 \\
\hline North-western & $10.0(7.6-12.3)$ & 48.2 & 8573 & 6231 & 20.9 & 75.4 & 5035 & 2154 \\
\hline North-central & $9.6(7.3-11.1)$ & 44.3 & 7522 & 5168 & 21.7 & 75.3 & 5698 & 2221 \\
\hline Uva & $6.8(2.4-11.1)$ & 47.0 & 5992 & 6296 & 20.8 & 72.8 & 3879 & 2266 \\
\hline$P$ value & $<0.001 \ddagger$ & $<0.001 \dagger$ & $<0.001 \uparrow$ & $<0.001 \uparrow$ & $<0.001 \dagger$ & $<0.001 \uparrow$ & & \\
\hline
\end{tabular}

$\left[\$-\right.$ crude prevalence of diabetes, $\uparrow-$ based on ANOVA, $\ddagger-$ based on $\chi^{2}$ test. $\uparrow$ Met-minutes per week. $*$ Data from Household Income and Expenditure Survey - 2006/07 (http://www.statistics.gov.lk/poverty/PovertyIndicators.pdf - Department of Census and Statistics Sri Lanka, 2008)] 
(a)

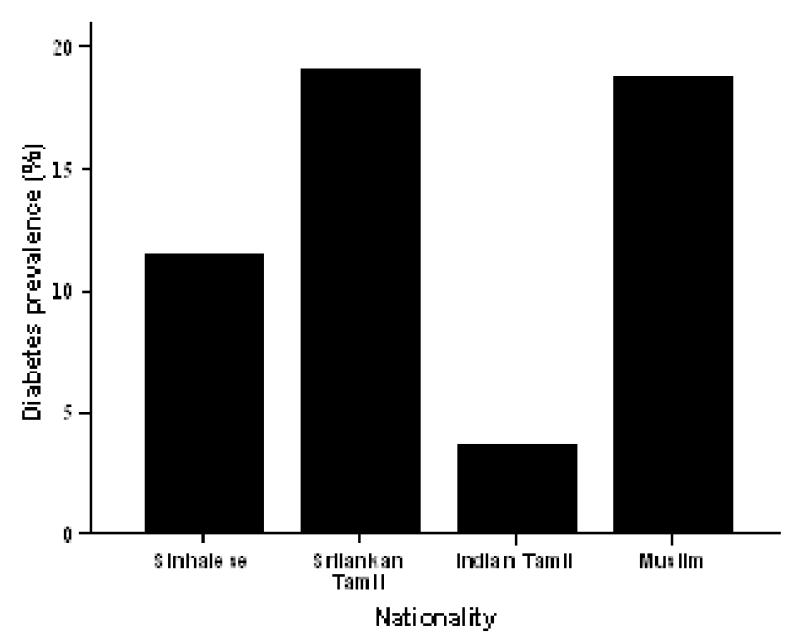

(c)

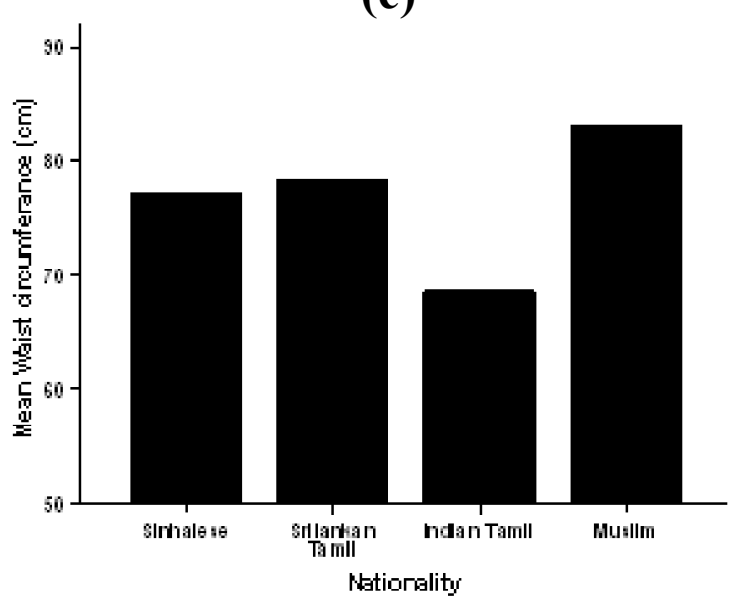

(e)

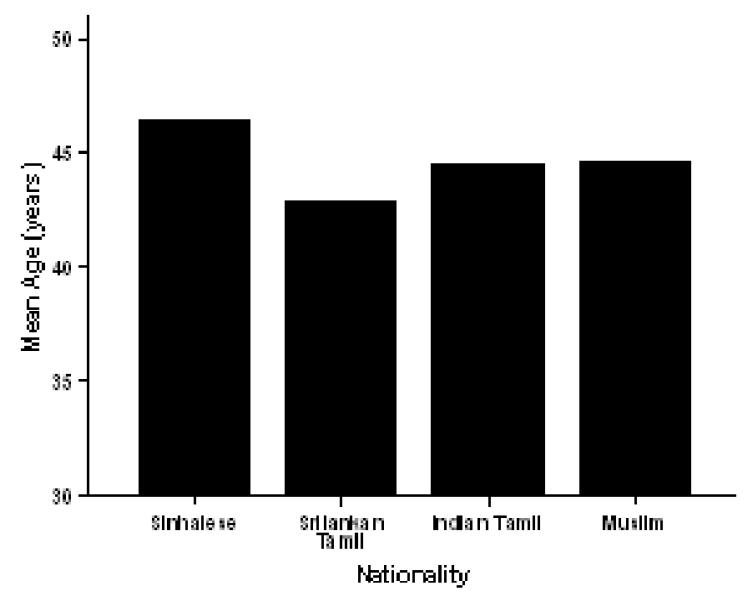

(b)

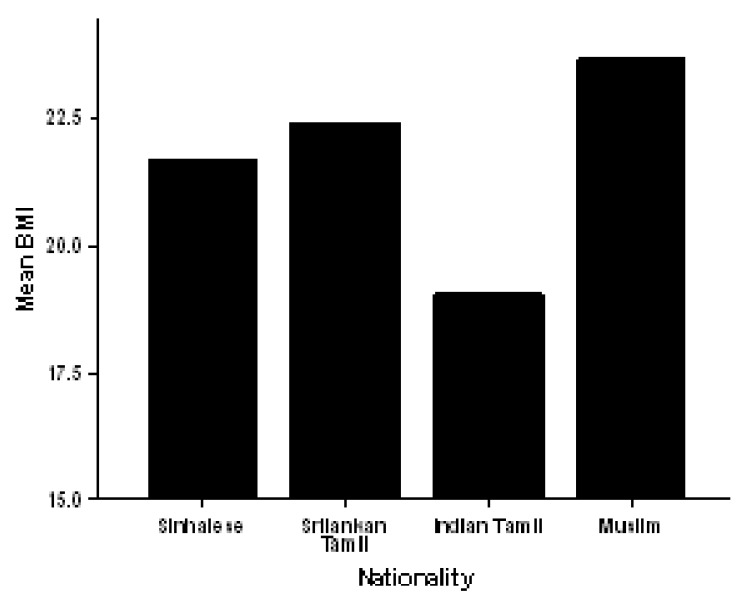

(d)

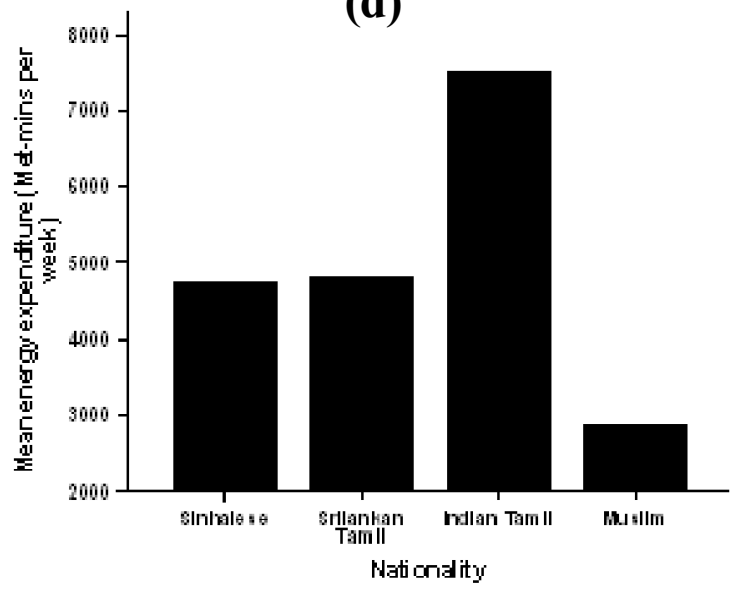

(f)

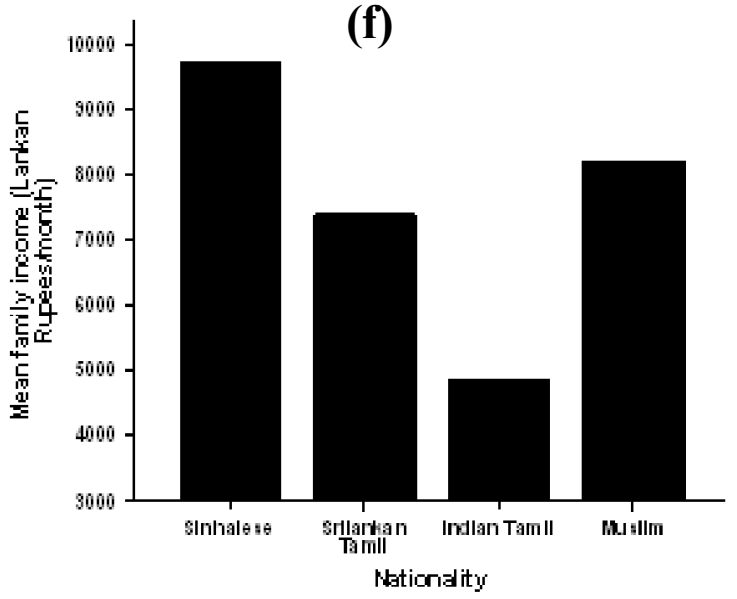

[a-prevalence of diabetes, $b-$ mean BMI, $c$ - mean waist circumference, $d$-mean energy expenditure activity), $\mathrm{e}-$ mean age, $\mathrm{f}-$ mean family income]

Figure 2. Prevalence of diabetes and the distribution of risk factors and socio-demographic correlates among different ethnic groups in Sri Lanka 
Table 2. Ethnic specific prevalence of diabetes, underlying risk factors and socio-demographic correlates

\begin{tabular}{|c|c|c|c|c|c|c|c|}
\hline Ethnicity & $\begin{array}{l}\text { Prevalence } \\
\text { of diabetes } \\
(95 \% \mathrm{CI})\end{array}$ & $\begin{array}{l}\text { Number } \\
(\%)\end{array}$ & $\%$ Urban & $\begin{array}{l}\text { Mean } \\
\text { age } \\
\text { (years) }\end{array}$ & $\begin{array}{l}\text { Mean } \\
\text { waist } \\
\text { circumference } \\
(\mathrm{cm})\end{array}$ & $\begin{array}{l}\text { Mean } \\
\text { Met- } \\
\text { minutes* }\end{array}$ & $\begin{array}{l}\text { Mean } \\
\text { family } \\
\text { income } \\
(L K R)\end{array}$ \\
\hline Sinhalese & $11.9(10.6-13.1)$ & $3877(86.4)$ & $15.8 \%$ & 46.9 & 77.4 & 4617 & 9694 \\
\hline Sri Lankan Tamil & $22.1(15.2-29.1)$ & $136(3.0)$ & $58.8 \%$ & 43.6 & 79.0 & 4629 & 7378 \\
\hline Indian Tamil & $3.2(0.3-6.1)$ & $163(3.6)$ & $3.7 \%$ & 46.5 & 67.8 & 7282 & 4847 \\
\hline Muslim & $21.4(14.3-28.5)$ & $298(6.6)$ & $28.9 \%$ & 44.8 & 83.6 & 2904 & 8194 \\
\hline
\end{tabular}

[LKR - Sri Lankan Rupees $(1 £=200$ LKR), 11 subjects were from very minor ethnic groups, *Met-minutes per week]

\section{Conclusions and discussion}

In this first report of province and ethnic specific prevalence of diabetes in Sri Lanka, we report a marked variation in the prevalence of diabetes among different provinces in Sri Lanka. The pattern of distribution of diabetes closely resembled that of obesity (waist circumference more than the BMI) and the level of income. Diabetes prevalence in the different provinces had an inverse relationship with the physical activity level. Although the income level was higher in the affluent provinces that had high prevalence of diabetes, the percapita energy expenditure followed an opposite pattern. Therefore, it is likely that physical inactivity plays a vital role in determining the difference in diabetes in different provinces and ethnic groups, and in fact seems to offer protection from diabetes when the energy consumption is higher. The mean Met-minutes in all provinces except the Western province is above 3000 Met-minutes which is the cut-off level for the 'Physically active' category according to the IPAQ guidelines.

In the multiple logistic regression analysis, ethnicity did not remain significantly associated with diabetes when it was examined together with other co-variants (obesity, physical activity, province of residence, income, occupation, family history, hypertension and lipid parameters). This suggests the possibility that the differences in diabetes in many sub ethnic groups within a major ethnic entity would be due to the differences in socioeconomic and lifestyle factors that result in different levels of obesity.

Our data indicate the need for higher levels of energy restriction and much higher levels of physical activity for protection from diabetes for South Asians.

\section{Public health importance of these findings and future research}

The province and ethnic specific prevalence of diabetes will be very useful in planning future interventions to control the diabetes epidemic in Sri Lanka and for resource allocation. According to the province specific data, there is an indication for the need for higher levels of physical activity (than the usual five days per week moderate exercise, that is equivalent to 600 Met-minutes) and lower levels of energy consumption to be free from diabetes in South Asians. This needs to be studied using interventional models of diabetes prevention in high risk ethnic groups.

\section{Acknowledgements}

The National Science Foundation of the Ministry of Science and Technology of Sri Lanka was the main source of funding for this study. The Oxford Centre for Diabetes Endocrinology and Metabolism provided support for data management. All individuals and organisations that supported the Sri Lanka Diabetes and Cardiovascular Study are acknowledged (www.OCDEM.com/SLDCS).

Conflicts of interest: Authors have no conflicts of interest to declare.

\section{References}

1. World Health Organization. The world health report 2002. Reducing risks, promoting healthy life. Geneva: World Health Organization, 2002.

2. World Health Organization. Noncommunicable diseases in South-East Asia region. A profile. New Delhi: World Health Organization, 2002. 
3. Jafar TH, Levey AS, Jafary FH, White F, Gul A, et al. Ethnic subgroup differences in hypertension in Pakistan. Journal of Hypertension 2003; 21: 905-12.

4. Singh RB, Bajaj S, Niaz MA, Rastogi SS, Moshiri M. Prevalence of type 2 diabetes mellitus and risk of hypertension and coronary artery disease in rural and urban population with low rates of obesity. International Journal of Cardiology 1998; 66: 65-72.

5. Sayeed MA, Mahtab H, AkterKhanam P, Abdul Latif Z, Keramat Ali SM, et al. Diabetes and impaired fasting glycemia in a rural population of Bangladesh. Diabetes Care 2003; 26: $1034-9$.

6. United Nations. United Nations Populations Prospects. New York: United Nations Populations Division, Department of Economic and Social Affairs, 2006. Available at http://www.un.ord/esa/population/unpop.htm Last accessed 17 February 2006.

7. Illangasekera U, Nugegoda DB, Perera LS. Prevalence of diabetes mellitus and impaired glucose tolerance in a rural Sri Lankan community. Ceylon Medical Journal 1993; 38: 123-6.

8. Illangasekera U, Rambodagalla S, Tennakoon S. Temporal trends in the prevalence of diabetes mellitus in a rural community in Sri Lanka. Royal Society of Health 2004;124: $92-4$.

9. Fernando DJ, Siribaddana S, de Silva D. Impaired glucose tolerance and diabetes mellitus in a suburban Sri Lankan community. Postgraduate Medical Journal 1994; 70: $347-9$.

10. Malavige GN, de Alwis NM, Weerasooriya N, Fernando DJ, Siribaddana SH. Increasing diabetes and vascular risk factors in a sub-urban Sri Lankan population. Diabetes Research and Clinical Practice 2002; 57: 143-5.

11. Mendis S, Ekanayake EM. Prevalence of coronary heart disease and cardiovascular risk factors in middle aged males in a defined population in central Sri Lanka. International Journal of Cardiology 1994; 46: 135-42.

12. Wijewardene K, Mohideen MR, Mendis S, Fernando DS, Kulathilaka T, et al. Prevalence of hypertension, diabetes and obesity: baseline findings of a population based survey in four provinces in Sri Lanka. Ceylon Medical Journal 2005; 50: 62-70.

13. Katulanda P, Constantine GR, Mahesh JG, Sheriff R, Seneviratne RDA, et al. Prevalence and projections of diabetes and pre-diabetes in adults in Sri Lanka - Sri Lanka Diabetes, Cardiovascular Study (SLDCS). Diabetes UK 2008; 25: 1062-69.

14. World Health Organization. Report of a WHO Expert Committee: physical status: the use and interpretation of anthropometry. World Health Organization Technical Report Series 1995; 854: 427-31.

15. World Health Organization. Definition, Diagnosis and Classification of Diabetes Mellitus and its Complications. Report of a WHO Consultation. Part 1. Diagnosis and Classification of Diabetes Mellitus. Document number WHO/NCD/NCS/99.2. Geneva: World Health Organization, 1999.

16. American Diabetes Association. Report of the Expert Committee on the Diagnosis and Classification of Diabetes Mellitus. Diabetes Care 1997; 20: 1183-97.

17. Craig CL, Marshall AL, Sjostrom M, Bauman AE, Booth $\mathrm{ML}$, et al. International physical activity questionnaire: 12country reliability and validity. Medicine and Science in Sports and Exercise 2003; 35: 1381-95.

18. Department of Census and Statistics in Sri Lanka. District Level Data-Population Characteristics. Census of Population and Housing. Colombo: Department of Census and Statistics in Sri Lanka, 2001. Data on CD. Available at http://www.statistics.gov.1k/PopHouSat/PDF/ p14\%20Table\%20Lists\%20of\%20the\%20CDs.pdf Last accessed 1 February 2006. 